\title{
Pemaknaan Dan Penerapan Prinsip Resiprositas Berdasarkan ASEAN Banking Integration Framework
}

\author{
Inda Rahadiyan \\ Fakultas Hukum Universitas Islam Indonesia \\ JIn. Tamansiswa No. 158 Yogyakarta \\ indarahadiyan1@gmail.com
}

Received: 5 Februari 2019; Accepted: 20 September 2019; Published: 17 Februari 2019

DOI: 10.20885/iustum.vol26.iss3.art6

\begin{abstract}
The reciprocity principle is the main principle in the integration of banking service in the ASEAN region, where it is scheduled to take place in 2020. The banking industry is complex and strictly regulated, therefore, research on the meaning of reciprocity in the ASEAN Banking Integration Framework (ABIF) becomes an interesting and relevant study. The problems examined in this study include: first, how are the meaning and the legal binding power of the reciprocity principle based on ABIF? Second, how is the Indonesian Government's effort to implement the reciprocity principle based on ABIF? This research was conducted by using normative method. The results of the study concluded that, first, the reciprocity principle based on ABIF is a basic principle of reciprocal treatment between member countries aimed at realizing ease of access and banking operational flexibility. This principle does not apply automatically and without conditions, but is based on the commitment and readiness of each country. Second, the Indonesian Government's efforts to implement the reciprocity principle have been carried out through the issuance of Law Number 4 of 2018 on the Ratification of the Protocol to Implement the Sixth Commitment Package in Financial Services in the ASEAN Framework in Services.
\end{abstract}

Keywords: Reciprocity principle; ABIF; Indonesia

\begin{abstract}
Abstrak
Prinsip timbal balik (resprositas) merupakan prinsip utama dalam upaya integrasi perbankan di kawasan ASEAN, dimana integrasi perbankan diagendakan terlaksana pada tahun 2020. Industri perbankan bersifat rumit dan diatur secara ketat, sehingga, penelitian mengenai pemaknaan prinsip resiprositas dalam kerangka ASEAN Banking Integration Framework (ABIF) menjadi suatu hal yang menarik dan relevan untuk dilakukan. Permasalahan yang dikaji dalam penelitian ini meliputi; pertama, bagaimana pemaknaan dan kekuatan mengikat prinsip resiprositas berdasarkan ABIF? Kedua, bagaimana upaya Pemerintah Indonesia dalam rangka mengimplementasikan prinsip resiprositas berdasarkan ABIF? Penelitian ini dilakukan dengan menggunakan metode penelitian normatif. Hasil penelitian menyimpulkan: pertama, prinsip resiprositas berdasarkan ABIF adalah sebuah prinsip dasar perlakuan timbal balik antar negara anggota yang ditujukan guna mewujudkan kemudahan akses dan fleksibiltas operasional perbankan. Prinsip ini tidak berlaku secara serta merta dan tanpa syarat, melainkan berdasarkan pada komitmen dan kesiapan masing-masing negara. Kedua, upaya pemerintah Indonesia dalam mengimplementasikan prinsip resiprositas telah dilakukan melalui penerbitan Undang-Undang Nomor 4 Tahun 2018 tentang Pengesahan Protokol Untuk Melaksanakan Paket Komitmen Keenam Bidang Jasa Keuangan Dalam Kerangka Kerja ASEAN Di Bidang Jasa.
\end{abstract}

Kata-kata Kunci: Prinsip resiprositas; ABIF; Indonesia 


\section{Pendahuluan}

Integrasi perbankan ASEAN dilaksanakan dalam sebuah kerangka aturan ASEAN Banking Integration Framework (ABIF). Pelaksanaan integrasi perbankan didasarkan pada dua kondisi mendasar, yakni (1) kesiapan negara anggota yang ditindaklanjuti melalui pembuatan komitmen dan (2) keberadaan bank-bank yang telah memenuhi kualifikasi sebagai bank ASEAN (Qualified ASEAN Banks /QABs).

Pelaksanaan integrasi perbankan didasarkan pada kesiapan (readiness) negara anggota. Selain kesiapan, integrasi perbankan harus pula dilaksanakan berdasarkan prinsip resiprositas. ASEAN Economic Community Blueprint secara eksplisit memberikan landasan bagi eksistensi prinsip resiprositas sebagai dasar integrasi perbankan: ${ }^{1}$

'...provide greater market access and operational flexibility for Qualified ASEAN Banks (QABs) through the ASEAN Banking Integration Framework (ABIF), based on each country's readiness and on a reciprocal basis, thereby reducing gaps in market access and operational flexibility across ASEAN.'

Berdasarkan ASEAN Economic Community Blueprint dimaksud, jelas bahwa integrasi perbankan ASEAN harus dilaksanakan berdasarkan prinsip resiprositas. ${ }^{2}$

Hakikatnya, prinsip resiprositas memiliki keterkaitan erat dengan prinsip non diskriminasi sebagaimana diatur dalam World Trade Organization (WTO). Sistem WTO menentukan adanya kewajiban pemberian perlakuan secara seimbang antar negara anggota. Pemberian perlakuan secara seimbang ini menjadi bagian tidak terpisahkan dari upaya perwujudan sistem perdagangan yang lebih bebas. Perdagangan dalam konteks ini mencakup perdagangan barang dan jasa. ${ }^{3}$

Menurut sistem WTO, baik perdagangan barang maupun jasa tunduk pada prinsip non diskriminasi (non-discrimination principle) yang diturunkan ke dalam dua prinsip utama yakni most-favoured nation dan national treatment. Kedua prinsip tersebut berlaku bagi seluruh negara anggota secara automatic and unconditional (serta merta dan tanpa syarat). ${ }^{4}$

\footnotetext{
1 ASEAN Economic Community Blueprint 2025, BAB III No. A4 huruf b hlm. 8

${ }^{2}$ Lihat: Sofi Suryasnia, et.all., Banking Strategy and Implementation of Banking ASEAN Integration Framework. (ABIF) in ASEAN Community (AEC)'s Era 2020, diakses dari https://mpra.ub.uni-muenchen.de/73303 diakses pada tanggal 10 Juli 2018 pukul 10.56 WIB

${ }^{3}$ Peter Van Den Bosch, WTO: Text, Cases and Materials, Cambridge University Press, 2008, hlm. 308

${ }^{4}$ Ibid.
} 
Berlakunya prinsip most-favoured nation mendapat pengecualian berdasarkan sistem WTO. Salah satu pengecualian dimaksud adalah melalui pembentukan free trade area. Artinya, prinsip most-favoured nation tidak lagi menjadi prinsip yang berlaku secara serta merta dan tanpa syarat terhadap negara-negara anggota WTO yang tergabung dalam sebuah kawasan perdagangan bebas.

Kembali pada persoalan prinsip resiprositas dalam integrasi perbankan ASEAN, menjadi penting dan menarik untuk dikaji persoalan pemaknaan dan kekuatan mengikat prinsip resiprositas berdasarkan kerangka ABIF. Urgensi pengkajian dimaksud terutama berkaitan dengan dua persoalan mendasar. Pertama, apakah prinsip resiprositas berdasarkan ABIF memiliki kekuatan mengikat yang bersifat automatic and unconditional sebagaimana prinsip non diskriminasi dalam WTO. Kedua, bagaimana upaya yang telah dilakukan oleh pemerintah Indonesia dalam rangka menerapkan prinsip resiprositas.

Upaya pemerintah dalam menerapkan prinsip resiprositas berdasarkan kerangka ABIF menjadi persoalan tersendiri yang perlu digarisbawahi. Hal ini dapat dipahami mengingat implementasi integrasi perbankan ASEAN diagendakan pada tahun 2020 mendatang. Seluruh upaya Pemerintah dalam pelaksanaan integrasi perbankan diharapkan sesuai dengan kepentingan Indonesia terhadap perwujudan asas keseimbangan yang menjiwai semangat integrasi perbankan itu sendiri. ${ }^{5}$

\section{Rumusan Masalah}

Permasalahan yang dikaji dalam penelitian ini meliputi; Pertama, bagaimana pemaknaan dan kekuatan mengikat prinsip resiprositas berdasarkan ASEAN Banking Integration Framework? Kedua, bagaimana upaya yang dilakukan oleh pemerintah Indonesia dalam rangka mengimplementasikan prinsip resiprositas berdasarkan ASEAN Banking Integration Framework?

\section{Tujuan Penelitian}

Penelitian ini bertujuan untuk: pertama, mengetahui dan menganalisis pemaknaan dan kekuataan mengikat prinsip resiprositas berdasarkan ASEAN

\footnotetext{
${ }^{5}$ Baca: ASEAN Economic Community Blueprint 2025, Loc. Cit
} 
Banking Integration Framework. Kedua, mengetahui dan menganalisis upaya yang dilakukan oleh pemerintah Indonesia dalam rangka mengimplementasikan prinsip resiprositas berdasarkan ASEAN Banking Integration Framework.

\section{Metode Penelitian}

Metode yang digunakan dalam rangka menjawab rumusan masalah dalam penelitian ini adalah metode penelitian hukum normatif. Penelitian ini menggunakan dua pendekatan yakni pendekatan konseptual dan pendekatan peraturan perundang-undangan. Penelitian hukum normatif dilakukan melalui studi kepustakaan dengan mengumpulkan, mempelajari serta menganalisis bahanbahan hukum primer, sekunder serta tersier. Analisa dan hasil penelitian kemudian disajikan secara kualitatif sesuai relevansinya terhadap rumusan masalah. ${ }^{6}$

\section{Hasil Penelitian dan Pembahasan}

Pemaknaan dan Kekuatan Mengikat Prinsip Resiprositas Berdasarkan ASEAN Banking Integration Framework

Integrasi perbankan ASEAN dilaksanakan dalam suatu kerangka aturan ASEAN Banking Integration Framework (ABIF). Pengaturan kerangka dasar pelaksanaan integrasi perbankan berdasarkan ABIF memiliki tujuan utama dalam rangka menyiapkan akses pasar dan fleksibilitas operasional bagi bank-bank negara anggota ASEAN. Keterbukaan akses pasar dan fleksibilitas operasional perbankan ASEAN dalam jangka panjang diharapkan mampu memberikan kontribusi bagi pertumbuhan ekonomi kawasan. ${ }^{7}$

Pembicaraan mengenai integrasi perbankan berdasarkan kerangka aturan ABIF tidak dapat dipisahkan dari eksistensi prinsip resiprositas (timbal balik). Hal demikian dapat dipahami mengingat integrasi perbankan ASEAN harus berlandaskan pada prinsip resiprositas sebagaimana tertuang dalam ASEAN Economic Community Blueprint (AEC Blueprint).

${ }^{7}$ Baca: Maria Socorro Gochoco and Eli M. Remolona, "The Promises of Bank Integration in ASEAN: Is There a Catch?”, ASEAN@50 Volume 5, The ASEAN Economic Community into 2025 and Beyond, 2017, hlm. 2
}

${ }^{6}$ Lihat: Johny Ibrahim, Teori dan Metodologi Penelitian Normatif, Banyumedia Publishing, Malang, 2006, hlm. 
AEC Blueprint secara eksplisit menyebut eksistensi prinsip resiprositas sebagai dasar integrasi perbankan sesuai dengan rumusan: "provide greater market access and operational flexibility for Qualified ASEAN Banks (QABs) through the ASEAN Banking Integration Framework, based on each countries readiness and on a reciprocal basis, thereby reducing gaps in market access and operational flexibility across ASEAN."8

Integrasi perbankan ASEAN harus dilaksanakan berdasarkan prinsip resiprositas. ${ }^{9}$ Resiprositas menjadi prinsip utama ABIF dimana akses pasar dan fleksibilitas operasional harus bersifat saling menguntungkan dan dapat diterima oleh negara yang bersepakat. ${ }^{10}$

Pelaksanaan integrasi perbankan dilakukan melalui dua tahapan. Pertama yakni tahapan multilateral dan kedua yakni tahapan bilateral. Tahapan multilateral diwujudkan melalui kesepakatan seluruh negara anggota ASEAN. Tahapan bilateral dilakukan melalui pembuatan perjanjian antar negara (bilateral agreement) atas dasar kesiapan (readiness). ${ }^{11}$

Tahapan multilateral telah selesai dilaksanakan sesuai dengan kesepakatan pembentukan ASEAN Economic Community. Masing-masing negara anggota sepakat untuk melaksanakan integrasi perbankan sebagai bagian yang tidak terpisahkan dari integrasi ekonomi ASEAN. ${ }^{12}$

Percepatan pembentukan MEA disepakati dalam KTT ASEAN ke-12 yang diselenggarakan pada bulan Januari 2007 melalui penandatanganan "Declaration on the Acceleration of the Establishment of an ASEAN Community by 2015". Sebagai tindak lanjut atas kesepakatan tersebut, para Menteri Ekonomi ASEAN kemudian menginstruksikan kepada Sekretariat ASEAN untuk menyusun sebuah Cetak Biru ASEAN Economic Community ${ }^{13}$ yang memuat empat pilar utama:

8 ASEAN Banking Integration Framework, http://www.asean.org diakses pada tanggal 27 Agustus 2018.

${ }^{9}$ Lihat: Sofi Suryasnia, et.all., Op. Cit.

10 ASEAN Economic Community Blueprint, loc.cit.

11 Pada kenyataannya, kesiapan masing-masing negara anggota ASEAN untuk melaksanakan integrase masih dihadapkan pada persoalan disparitas. Uraian mengenai ini antara lain dapat dibaca dalam: Marcella Dwi Permatasari, "Upaya ASEAN Menghadapi Disparitas Finansial Dalam Proses Integrasi Finansial Regional: Studi Kasus ASEAN Banking Integration Framework (ABIF)", Jurnal Analisis Hubungan Internasional, Volume 5 Nomor 3, Oktober 2016. Baca pula: Asian Development Bank, The Road to ASEAN Financial Integration: A Combined Study on Assessing the Financial Landscape and Formulating Milestones for Monetary and Financial Integration in ASEAN, Asian Development Bank, Mandaluyong City, 2013.

${ }_{12}$ Baca: ASEAN Economic Community Blueprint, Loc. Cit.

13 Direktorat Kerjasama ASEAN, ASEAN Selayang Pandang Edisi ke-19, Jakarta, hlm. 33. 
(1) ASEAN sebagai pasar tunggal dan basis produksi tunggal yang didukung dengan elemen aliran bebas barang, jasa, tenaga kerja terdidik dan aliran modal yang lebih bebas;

(2) ASEAN sebagai kawasan yang berdaya saing tinggi di bidang ekonomi dengan elemen peraturan kompetisi, perlindungan konsumen, hak atas kekayaan intelektual, pengembangan infrastruktur, perpajakan dan $e$ commerce;

(3) ASEAN sebagai kawasan pengembangan ekonomi yang bersifat merata dengan elemen pengembangan usaha kecil dan menengah serta prakarsa integrasi ASEAN untuk negara-negara Kamboja, Laos dan Vietnam;

(4) ASEAN sebagai kawasan yang terintegrasi penuh dengan perekonomian global

Pembentukan ASEAN Economic Community merupakan perwujudan dari Visi ASEAN 2020. ${ }^{1}$ Menurut Visi ASEAN 2020, pembentukan masyarakat ekonomi ASEAN bertujuan untuk mewujudkan suatu kawasan yang:14 " a stable, prosperous and highly competitive ASEAN Economic Region in which there is a free flow of goods, services and investments, a freer flow of capital, equitable economic development and and reduced poverty and socio-economic disparities." 15

Visi ASEAN 2020 telah menjadi sebuah kesepakatan baru mengenai integrasi ekonomi. Kesepakatan ini dapat pula dipandang sebagai kelanjutan dari kesepakatan ASEAN Free Trade Area (AFTA). Apabila dipandang dari perspektif investasi, integrasi ekonomi berdasarkan Visi ASEAN 2020 guna membentuk kawasan ASEAN sebagai single production base diyakini sebagai langkah besar dalam menarik minat investor. ${ }^{16}$

Integrasi ekonomi ASEAN dimaknai sebagai kesepakatan guna membentuk Asia Tenggara sebagai sebuah pasar tunggal (single market) dan basis produksi tunggal (production base) melalui pembebasan aliran barang, jasa, tenaga kerja terampil (skilled labor) serta arus penanaman modal yang lebih bebas (freer flow of capital) antar negara anggota. ${ }^{17}$

Melalui kesepakatan tersebut negara-negara anggota berharap agar kesenjangan pembangunan (development gap) di antara negara-negara ASEAN-6

\footnotetext{
14 “ASEAN Vision 2020”, http://www.aseansec.org_diakses pada tanggal 30 Juni 2018.

${ }^{15}$ Ibid.

${ }^{16}$ Koesrianti, "Analisa Kekuatan Mengikat Piagam ASEAN dan Perkembangan Mekanisme Penyelesaian Sengketa di ASEAN," Jurnal Yuridika, Volume 26 No. 1, Januari-April 2011, hlm. 56

17 ASEAN Economic Community Blueprint, Loc. Cit.
} 
dengan CLMV (Cambodia, Laos, Myanmar, Vietnam) dapat dihapuskan atau setidaknya dapat diperkecil. ${ }^{18}$ Persoalan kesenjangan antar dua kelompok negara anggota ASEAN menjadi sangat krusial mengingat hal ini merupakan salah satu faktor penghambat pelaksanaan integrasi ekonomi kawasan ASEAN. ${ }^{19}$

Sebagaimana telah disinggung, tahapan bilateral dalam rangka integrasi perbankan ASEAN dilaksanakan sesuai dengan kesiapan masing-masing negara anggota. Setiap negara anggota yang telah memiliki kesiapan dapat melakukan perjanjian bilateral dengan negara anggota lain. Demi tercapainya tujuan saling menguntungkan dan dapat diterima oleh negara yang bersepakat, maka ABIF baru dapat terlaksana terhadap negara-negara yang telah melakukan perjanjian bilateral terlebih dahulu.

Guna mewujudkan tujuan integrasi perbankan yang saling menguntungkan, Bank Indonesia mengusulkan agar pengaturan prinsip resiprositas dapat memuat dua ketentuan pokok:20

1) Bagi negara-negara ASEAN yang belum memiliki hubungan home-host, ${ }^{21}$ maka pengaturan terhadap prinsip resiprositas harus bertujuan untuk menciptakan peluang pendirian Qualified ASEAN Banks (QABs).

2) Bagi negara-negara ASEAN yang telah memiliki hubungan home-host, maka pengaturan terhadap prinsip resiprositas harus bertujuan untuk mengurangi kesenjangan dalam penyediaan akses pasar dan fleksibilitas operasional di negara ASEAN yang bersepakat.

Pada prakteknya, negara yang belum memiliki dasar hubungan home-host akan memperoleh kemudahan akses pasar dan fleksibilitas operasional setara dengan bank domestik di negara tujuan. Bagi negara yang telah memiliki dasar

\footnotetext{
${ }^{18}$ Koesrianti, Op. Cit., hlm. 58

${ }^{19}$ Uraian lebih mendalam mengenai permasalahan ini, baca: Maria Monica Wihardja, Financial Integration Challenges in ASEAN Beyond 2015, Centre for Strategic and International Studies, November 2013. Baca pula: Bank for International Settlement 2015, ASEAN Banking Integration and Lesson from Europe, http://www.bis.org/punl/qtrpdf/r_qt1509z.h diakses pada tanggal 10 Desember 2017

20 Inda Rahadiyan dan Berliana Rida, "Komitmen Indonesia dalam Penerapan Prinsip Resiprositas Berdasarkan ASEAN Banking Integration Framework", Laporan Penelitian Kolaborasi Dosen dan Mahasiswa, Program Studi Strata Satu Ilmu Hukum, Fakultas Hukum Universitas Islam Indonesia, 2016, hlm. 90.

${ }^{21}$ Hubungan home-host merupakan hubungan antara home country (negara asal investasi) dengan host country (negara tujuan investasi), yakni hubungan yang terjalin antara negara asal bank dengan negara tujuan ekspansi suatu bank. Uraian lebih mendalam mengenai hubungan antara home country dengan bost country dalam perspektif hukum investasi, antara lain dapat dibaca dalam: Stephan W. Schill, "International Investment Law and The Rule of Law", Amsterdam Law School Legal Studies Research Paper No. 2017-18, https://www/ilsa.org diakses pada tanggal 8 Desember 2017, Rudolf Dolzer, “The Impact of International Investment Treaties on Domestic Administrative Law", NYU Journal of International Law and Politics Vol. 37, Institute for International Law and Justice, 2005.
} 
hubungan home-host dapat meminta kepada negara tuan rumah untuk mengurangi adanya kesenjangan akses pasar dan fleksibilitas operasional.

Hal-hal yang mencakup kesenjangan akses pasar, antara lain; kesenjangan terhadap jumlah kantor cabang bank dan jumlah mesin Anjungan Tunai Mandiri. Kesenjangan fleksibilitas operasional mencakup kesenjangan proses pengajuan ijin kegiatan usaha antara bank domestik dengan bank asing. ${ }^{22}$

Penerapan prinsip resiprositas ABIF dilakukan dalam bentuk pertukaran akses pasar dan fleksibilitas operasional perbankan antara dua negara atau lebih yang dilakukan atas dasar saling menguntungkan dan dapat diterima oleh masingmasing negara yang bersepakat. ${ }^{23}$

Berdasarkan rumusan AEC Bluperint, prinsip resiprositas dimaknai sebagai suatu prinsip dasar yang bersifat 'menghendaki adanya syarat-syarat tertentu'. Artinya, prinsip resiprositas dalam integrasi perbankan baru dapat diimplementasikan setelah terpenuhinya syarat tertentu. Persyaratan dimaksud yakni adanya perjanjian bilateral antar negara anggota berdasarkan kesiapan dan terpenuhinya kualifikasi QABs. ${ }^{24}$

Perjanjian bilateral antar negara anggota dalam rangka penerapan integrasi perbankan dilandaskan pada adanya kesiapan (readiness). Artinya, masing-masing anggota dapat melakukan perjanjian bilateral dengan negara anggota yang lain sesuai dengan kondisi kesiapan masing-masing.

Upaya persiapan suatu negara ditunjukkan dengan pemenuhan bank-bank dalam negeri terhadap kualifikasi QABs. Partisipasi suatu negara dalam implementasi ABIF juga memperhatikan kesiapan sektor keuangan masing-masing negara anggota ASEAN. Dalam hal ini, negara-negara ASEAN utama (ASEAN-6) akan saling membantu kesiapan negara ASEAN lainnya dalam proses percepatan integrasi perbankan melalui dukungan pendidikan, pelatihan dan tenaga ahli.25

\footnotetext{
22 Baca: Bank Indonesia, Siaran Pers tanggal 31 Desember 2014 'Indonesia Sepakat Mendukung Integrasi Perbankan ASEAN, diakses dari https://www.bi.go.id pada tanggal 10 Desember 2016 pada pukul 9.11 WIB

${ }^{23}$ Bank Indonesia, Ibid.

${ }^{24}$ Bank-bank yang masuk dalam kualifikasi QABs wajib memenuhi kriteria tertentu. Kriteria dimaksud meliputi: (1) strong and well managed bank, (2) Indegenous ASEAN bank, (3) meets the prudential requirements. Uraian lebih mendalam mengenai ini, baca: Yati Kurniati, "ASEAN Banking Integration Framework: Advances and Challenges in Regional Integration”, https://www.imf.org/external/np/seminars/eng/2016/hit2016/pdf/2-2.pdf diakses tanggal 10 Desember 2017.

25 Siaran Pers OJK, Loc. Cit.
} 
Pada sisi yang lain, perjanjian bilateral antar negara anggota bertujuan untuk mengurangi hambatan yang dialami oleh bank-bank dari negara yang bersepakat dan mencegah terjadinya ketimpangan akses pasar.

Upaya untuk mengurangi kesenjangan terhadap akses pasar antar negara anggota menjadi sebuah tujuan penting mengingat negara-negara anggota ASEAN masih terbagi ke dalam dua kelompok berdasarkan kekuatan ekonomi. Kelompok pertama yakni ASEAN-6 (Singapura, Malaysia, Indonesia, Thailand, Filipina dan Brunei Darussalam). Kelompok kedua yakni negara-negara anggota lainnya. Artinya, pelaksanaan integrasi perbankan masih dihadapkan pada kesenjangan antar negara anggota (ASEAN still faces challenges of a sizeable gap between ASEAN countries). ${ }^{26}$

Keterbukaan akses pasar dan fleksibilitas operasional diberlakukan khusus bagi bank-bank yang telah memenuhi kualifikasi QABs. Dengan perkataan lain, predikat sebagai QABs adalah syarat utama yang wajib diperoleh agar suatu bank dapat melakukan ekspansi ke pasar ASEAN. ${ }^{27}$

Kriteria QABs merupakan kriteria tertentu yang disepakati oleh masingmasing negara anggota ASEAN. Beberapa diantara kriteria QABs yakni; memiliki permodalan yang kuat (well capitalized), direkomendasikan oleh otoritas perbankan (recommended by authorities), memiliki pengelolaan yang baik (well managed) serta memenuhi ketentuan kehati-hatian sesuai dengan standard internasional (pass the Basel provisions). ${ }^{28}$

Standard kehati-hatian sebagai kriteria QABs adalah standard kehati-hatian sebagaimana diatur dalam prinsip Basel. Indonesia telah melakukan pemenuhan terhadap tiga standar utama Basel II dan III. Ketiga standar dimaksud yakni; (1) Basel III-Final Capital Framework Issued, (2) Basel III-Final Liquidity Framework Issued, serta (3) Basel II-full implementation. ${ }^{29}$

Sistem perdagangan internasional sebagaimana diatur oleh World Trade Organization (WTO), menempatkan prinsip keseimbangan juga menjadi tujuan utama dari upaya perwujudan sistem perdagangan yang lebih bebas. Perdagangan

\footnotetext{
${ }^{26}$ Yati Kurniati, Loc. Cit.

27 Sofi Suryasnia, et.all., Op. Cit., hlm. 3

${ }^{28}$ Marchella Dwi Permatasari, Op. Cit.

${ }^{29}$ Baca: Yati Kurniati, Loc. Cit.
} 
dalam konteks ini mencakup perdagangan barang dan jasa. ${ }^{30}$ Berdasarkan sistem WTO, baik liberalisasi perdagangan barang maupun jasa tunduk pada prinsip non diskriminasi (non-discrimination principle) yang diturunkan ke dalam dua prinsip utama yakni most favoured nation dan national treatment. Secara mendasar kedua prinsip tersebut berlaku bagi seluruh negara anggota secara automatic and unconditional (serta-merta dan tanpa syarat). ${ }^{31}$

Berlakunya prinsip non diskriminasi dapat dikesampingkan dalam beberapa hal. Salah satu di antara pengecualian atas prinsip non diskriminasi yakni pembentukan blok-blok kerjasama ekonomi regional dan Free Trade Area (FTA). Artinya, prinsip non diskriminasi yang berlaku secara universal berdasarkan sistem WTO, dapat dikecualikan oleh negara-negara yang tergabung dalam suatu kerjasama ekonomi regional.

Berdasarkan uraian di atas, maka prinsip resiprositas berdasarkan ABIF bermakna sebagai sebuah prinsip dasar hubungan timbal balik antar negara anggota dalam pelaksanaan integrasi perbankan. Hubungan timbal balik berdasarkan ABIF meliputi hubungan timbal balik dalam penyediaan akses pasar dan fleksibiltas operasional bank.

Pemberlakukan prinsip resiprositas tidak bersifat serta-merta dan tanpa syarat. Berbeda dengan prinsip non diskriminasi sebagaimana diatur dalam WTO, pemberlakuan prinsip resiprositas didasarkan pada terpenuhinya dua syarat. Pertama, yakni tercapainya perjanjian bilateral antar negara anggota atas dasar kesiapan. Kedua, terpenuhinya kualifikasi /standard QABs bagi bank-bank negara anggota. Dengan demikian, prinsip resiprositas tidak secara serta-merta mengikat seluruh negara anggota ASEAN sejak tercapainya kesepakatan pembentukan ASEAN Economic Community.

Secara teoritis, pembahasan mengenai kekuatan mengikat prinsip resiprositas tidak dapat dilepaskan dari ruang lingkup hukum perbankan. Pemahaman mengenai ruang lingkup pengertian hukum perbankan perlu untuk diuraikan pula dalam kajian ini mengingat prinsip resiprositas lahir dari kaidah hukum

\footnotetext{
${ }^{30}$ Peter Van Den Bosch, Loc. Cit.

${ }^{31}$ Ibid.
} 
internasional. Dengan memahami ruang lingkup hukum perbankan, maka akan didapatkan argumentasi konseptual yang turut menguatkan mengenai kekuatan berlakunya prinsip resiprositas yang bersumber dari hukum internasional.

Djuhmana mendefinisikan hukum perbankan sebagai kumpulan peraturan hukum yang mengatur kegiatan lembaga keuangan bank yang meliputi segala aspek. Aspek dimaksud meliputi aspek esensi, eksistensi serta hubungan antara perbankan dengan bidang-bidang kehidupan yang lain. ${ }^{32}$

Sebagai suatu sistem hukum, ruang lingkup pengaturan hukum perbankan meliputi:33

1) Asas-asas perbankan, seperti norma efisiensi, efektivitas, kesehatan bank, profesionalisme pelaku perbankan, maksud dan tujuan lembaga perbankan, hubungan serta hak dan kewajiban bank.

2) Pelaku perbankan, seperti direksi, dewan komisaris, serta seluruh pihak terafiliasi. Termasuk dalam hal ini adalah bentuk badan hukum bank, seperti Persero BUMN, BUMD, Perseroan Terbatas swasta serta koperasi.

3) Ketentuan-ketentuan perbankan yang dikhususkan bagi perlindungan kepentingan umum, seperti pencegahan pencucian uang, persaingan tidak sehat serta perlindungan nasabah.

Hermansyah memberikan definisi terhadap hukum perbankan dengan mendasarkan pada pengertian perbankan sebagai segala sesuatu menyangkut tentang bank, mencakup kelembagaan, kegiatan usaha, serta cara dan proses yang dilakukan oleh bank dalam melaksanakan kegiatan usahanya. Berdasarkan pengertian perbankan, maka Hermansyah mendefinisikan hukum perbankan sebagai keseluruhan norma-norma tertulis maupun norma-norma tidak tertulis yang mengatur tentang bank. Norma-norma dimaksud meliputi; kelembagaan, kegiatan usaha, serta cara dan proses yang dilakukan oleh bank dalam menjalankan kegiatan usahanya. ${ }^{34}$

Definisi mengenai hukum perbankan juga dikemukakan oleh Munir Fuady. Munir Fuady mendefinisikan hukum perbankan sebagai seperangkat norma hukum dalam bentuk peraturan perundang-undangan, yurisprudensi, doktrin beserta sumber hukum lainnya yang mengatur permasalahan-permasalahan perbankan.

32 Muhammad Jumhana, Hukum Perbankan di Indonesia, Bandung, Alumni, 1993, hlm. 10

${ }_{33}$ Djoni S. Gazali dan Rahmadi Usman, Hukum Perbankan, Cet. Ketiga, Jakarta, Sinar Grafika, 2016, hlm.

34 Hermansyah, Hukum Perbankan Nasional Indonesia, Jakarta, Kencana Prenada, 2005, hlm. 39. 
Pengaturan permasalahan perbankan meliputi; kelembagaan dan aspek kegiatan sehari-hari bankperilaku perbankan serta seluruh hak dan kewajiban bank. ${ }^{35}$

Berdasarkan pada pengertian hukum perbankan yang dikemukakan oleh para ahli, maka ruang lingkup hukum perbankan meliputi unsur-unsur: ${ }^{36}$

1) Sekumpulan ketentuan hukum perbankan. Ketentuan hukum perbankan muncul sebagai akibat dikeluarkannya berbagai peraturan perundangundangan. Seluruh peraturan perundang-undangan di bidang perbankan tersebut saling berkaitan dan membentuk sistem hukum perbankan.

2) Hukum perbankan bersumber dari norma tertulis dan norma tidak tertulis. Norma tertulis dibentuk oleh pihak-pihak berwenang dalam pembentukan peraturan perundang-undangan. Norma tidak tertulis bersumber dan terpelihara dalam praktek penyelenggaraan perbankan.

3) Hukum perbankan terdiri dari peraturan hukum dan asas-asas hukum perbankan. Termasuk dalam hal ini adalah struktur dan budaya hukum yang berkembang dalam hukum perbankan.

4) Hukum perbankan mengatur tata laksana kelembagaan bank. Berkaitan dengan kelembagaan bank, hukum perbankan mengatur segala sesuatu mengenai pendirian bank.

5) Hukum perbankan mengatur aspek-aspek kegiatan usaha bank serta cara dan proses yang dilakukan oleh bank dalam melaksanakan kegiatan usahanya.

Prinsip resiprositas sebagai bagian dari kaidah hukum perbankan yang bersumber dari perjanjian internasional, memiliki kekuatan mengikat bagi negaranegara anggota ASEAN. Kekuatan mengikat prinsip resiprositas ABIF berlaku bagi masing-masing negara yang telah melakukan perjanjian bilateral mengenai pelaksanaan integrasi perbankan. Dengan perkataan lain, prinsip resiprositas dalam rangka integrasi perbankan ASEAN baru dapat menjadi sebuah prinsip yang bersifat mengikat terhadap negara-negara anggota yang telah melakukan perjanjian bilateral.

\section{Upaya Indonesia Dalam Mengimplementasikan Prinsip Resiprositas Guna Menyongsong Integrasi Perbankan ASEAN 2020}

Perlakuan timbal balik berdasarkan prinsip resiprositas ABIF pada dasarnya hanya dapat dinikmati oleh bank-bank dari negara anggota ASEAN yang telah memenuhi kualifikasi QABs. Kualifikasi QABs meliputi tiga elemen penting yakni

${ }_{35}$ Munif Fuady, Hukum Perbankan Modern (Berdasarkan Undang-Undang Tabun 1998) Buku Ke Satu, Bandung, Citra Aditya Bakti, 1999, hlm. 14.

${ }^{36}$ Djoni S. Gazali, Op. Cit., hlm. 3-4 
kualitas permodalan, pengelolaan, serta daya tahan bank terhadap perubahan kondisi ekonomi. Selain menyiapkan daftar bank yang akan diproyeksikan bagi kualifikasi QABs, partisipasi suatu negara dalam implementasi prinsip resiprositas juga harus dilakukan dengan memperhatikan kesiapan sektor perbankan dalam negeri. ${ }^{37}$ Dalam konteks ini negara-negara ASEAN-6 diharapkan dapat saling membantu melalui dukungan pendidikan, pelatihan dan sertifikasi tenaga ahli. ${ }^{38}$

Prinsip resiprositas menjadi salah satu prinsip utama ABIF dimana akses pasar dan fleksibilitas operasional harus bersifat saling menguntungkan dan dapat diterima oleh masing-masing negara anggota yang bersepakat. Perlakuan timbal balik dan saling menguntungkan tetap dilaksanakan dalam koridor pemenuhan persyaratan prudensial bagi kandidat QABs yang akan masuk dan beroperasi di suatu negara ASEAN. ${ }^{39}$ Hal demikian sesuai dengan konsep dasar resiprositas sebagai sebuah prinsip timbal balik terhadap pertukaran akses pasar dan fleksibilitas operasional yang bersifat saling menguntungkan. ${ }^{40}$

Prinsip resiprositas dapat dilaksanakan oleh negara-negara yang telah melakukan perjanjian bilateral. Sementara itu bagi negara-negara ASEAN yang belum memiliki hubungan home-host ${ }^{41}$ berdasarkan perjanjian bilateral, maka pengaturan prinsip resiprositas ditujukan dalam rangka membentuk QABs. Dengan demikian pengaturan prinsip resiprositas dilakukan terhadap dua substansi utama, yakni: ${ }^{42}$

1) Bagi negara-negara yang belum memiliki hubungan bilateral pengaturan prinsip resiprositas ditujukan dalam rangka memenuhi kualifikasi QABs.

2) Bagi negara-negara yang telah memiliki hubungan bilateral pengaturan prinsip resiprositas ditujukan dalam rangka mengurangi kesenjangan penyediaan akses pasar dan fleksibilitas operasional.

Hubungan timbal balik antar negara yang belum memiliki hubungan homehost ditujukan guna memperoleh kemudahan dalam akses pasar dan fleksibilitas

${ }^{37}$ Secara mendasar upaya liberalisasi perbankan di kawasan ASEAN tidak terlepas pula dari berbagai risiko dan tantangan tersendiri. Untuk ini, baca: Alladin D. Rillo, “ASEAN Financial Integration: Opportunities, Risks and Challenges," Public Policy Review, Policy Research Institute, Ministry of Finance, Japan, Volume 14, Nomor 5, September 2018, hlm. 910.

38 Siaran Pers OJK, Loc. Cit.

39 Siaran Pers Bank Indonesia, Loc. Cit.

40 Buletin Bank Indonesia, Kajian Stabilitas Keuangan, 24 Maret 2015, hlm. 49

${ }^{41}$ Hubungan home-host merupakan hubungan antara home country dengan host country, yakni hubungan yang terjalin antara negara asal sebagai letak asal bank dengan negara tujuan sebagai letak yang hendak dijadikan tujuan. 42 Siaran Pers OJK, Loc. Cit. 
operasional. Kemudahan akses pasar dan fleksibilitas setara dengan perlakukan yang diberikan dan dinikmati oleh bank-bank domestik. Hubungan timbal balik antar negara yang telah memiliki hubungan home-host ditujukan dalam rangka mengurangi kesenjangan akses pasar dan fleksibilitas operasional.

Kesenjangan akses pasar meliputi adanya kesenjangan terhadap jumlah kehadiran bank, jumlah kantor cabang serta jumlah mesin Anjungan Tunai Mandiri (ATM). Kesenjangan fleksibilitas operasional mencakup kesenjangan kemudahan perizinan antara bank asing dibandingkan dengan kemudahan pemberian izin usaha yang diberikan kepada bank-bank domestik. ${ }^{43}$

Prinsip resiprositas berdasarkan ABIF juga diperlukan dalam rangka membentuk sebuah harmonisasi regulasi. Harmonisasi regulasi menjadi salah satu substansi penting bagi proses integrasi perbankan mengingat masing-masing negara anggota memiliki regulasi perbankan yang berbeda.

Perbedaan regulasi perbankan antar negara anggota terutama mengenai perizinan pendirian bank menjadi hambatan besar dalam perwujudan liberalisasi. Harmonisasi regulasi dimaksudkan terhadap dua hal. Pertama, mempersempit diskriminasi perlakuan antara bank domestik dengan bank asing. Kedua, membuka akses pasar dan fleksibilitas operasional bank antar negara.

Indonesia sebagai salah satu penggagas utama AEC memiliki komitmen terhadap pelaksanaan integrasi perbankan. Komitmen tersebut diwujudkan baik dalam tataran regulasi maupun dalam tataran non regulasi. Dalam tataran regulasi, upaya Indonesia untuk mengimplementasikan prinsip resiprositas telah mendapat pijakan yuridis yang kuat melalui penerbitan Undang-Undang Nomor 4 tahun 2018 tentang Pengesahan Protokol Untuk Melaksanakan Paket Komitmen Keenam Bidang Jasa Keuangan Dalam Kerangka Kerja ASEAN Di Bidang Jasa. ${ }^{44}$

${ }^{43}$ Bank Indonesia, Op. Cit., hlm. 48

${ }^{44}$ Undang-Undang Republik Indonesia Nomor 4 Tahun 2018 Tentang Pengesahan Protokol Untuk Melaksanakan Paket Komitmen Keenam Bidang Jasa Keuangan Dalam Kerangka Kerja ASEAN Di Bidang Jasa, Lembaran Negara RI tahun 2018 Nomor 82. 
Eksistensi prinsip resiprositas berdasarkan kerangka ABIF secara eksplisit disebut dalam bagian penjelasan Undang-Undang Nomor 4 Tahun 2018 dengan rumusan:45

Dalam perluasan akses pasar jasa keuangan di berbagai forum internasional (multilateral, regional, dan bilateral), Indonesia selalu berpegang pada prinsip-prinsip: (i) penambahan komitmen baru senantiasa memperhatikan komitmen Indonesia pada World Trade Organization (WTO) sebagai patokan, (ii) ikut sertanya Indonesia dalam perluasan akses pasar tidak terlepas dari pandangan ASEAN bahwa Indonesia adalah negara yang memiliki peran yang signifikan dalam mewujudkan Masyarakat Ekonomi ASEAN (peran leadership), (iii) perluasan akses pasar ditujukan pada pengembangan dan/atau penyehatan industri keuangan nasional, penerapan best practice operasional jasa keuangan, dan penciptaan lingkungan yang mendorong daya saing dan inovasi penyedia jasa keuangan domestik, (iv) membuka peluang bagi penyedia jasa keuangan dalam negeri yang memiliki kapasitas memadai untuk melakukan ekspansi ke negara ASEAN lainnya, seperti pada sektor perbankan melalui skema ASEAN Banking Integration Framework (ABIF), dan (v) peningkatan jumlah dan kualitas produk jasa keuangan yang terjangkau bagi konsumen dalam negeri baik dalam kedudukannya sebagai produsen maupun konsumen akhir.

Berdasarkan pada rumusan penjelasan umum Undang-Undang Nomor 4 Tahun 2018 sebagaimana dikutip, jelas bahwa kerangka kerja ABIF yang memuat prinsip resiprositas telah mendapat kekuatan berlaku secara yuridis berdasakan sistem hukum Indonesia.

Hingga 2018, komitmen Indonesia dalam mengimplementasikan prinsip resiprositas berdasarkan ABIF telah dilaksanakan dengan Malaysia. Komitmen kerjasama implementasi ABIF antara Indonesia dengan Malaysia meliputi:46

a. Indonesia dan Malaysia sepakat untuk mengizinkan tiga QABs beroperasi di masing-masing negara. Malaysia yang saat ini telah memiliki dua QAB yang beroperasi di Indonesia baru diizinkan untuk menambah QABs ketiga di Indonesia setelah tiga QABs Indonesia beroperasi penuh di Malaysia;

b. QABs Indonesia akan diperlakukan sama dengan bank domestik Malaysia dalam operasionalnya. Hal yang sama juga dilakukan Indonesia untuk QABs Malaysia, begitu pula sebaliknya untuk QABs Malaysia di Indonesia;

c. QABs Indonesia mendapatkan kelonggaran untuk memenuhi persyaratan modal minimum perbankan di Malaysia secara bertahap.

45 Bagian Umum Angka 1 Penjelasan Undang-Undang Nomor 4 Tahun 2018 tentang Pengesahan Protokol Untuk Melaksanakan Paket Komitmen Keenam Bidang Jasa Keuangan Dalam Kerangka Kerja ASEAN Di Bidang Jasa.

46 Bagian Umum Angka 1 Penjelasan Undang-Undang Nomor 4 Tahun 2018 tentang Pengesahan Protokol Untuk Melaksanakan Paket Komitmen Keenam Bidang Jasa Keuangan Dalam Kerangka Kerja ASEAN Di Bidang Jasa. 
Secara historis, Indonesia memiliki peran yang cukup besar atas terbentuknya kerangka ABIF. Indonesia memiliki peran cukup besar dalam pembahasan Guidelines ABIF. Peran Indonesia terutama ditujukan guna memperjuangkan prinsip resiprositas. Sebelum terbitnya Undang-Undang Nomor 4 Tahun 2018, Bank Indonesia telah menyampaikan usulan penerapan prinsip resiprositas dan kerangka pengaturan yang meliputi: ${ }^{7}$

1) Penekanan pada penerapan prinsip resiprositas, bahwa kesepakatan yang dicapai harus bersifat saling menguntungkan dan saling dapat diterima oleh negara-negara yang bersepakat;

2) Penerapan prinsip resiprositas diperkuat dengan ssemangat reducing the gaps (pengurangan kesenjangan) bagi negara-negara yang telah memiliki hubungan home-host;

3) Penetapan jumlah QABs dengan memeprhitungkan banking presence sebuah negara di negara anggota yang lain;

4) Bank-bank dari ASEAN yang telah hadir di negara ASEAN lainnya diprioritaskan sebagai kandidat QABs.

Berdasarkan pada usulan Bank Indonesia, maka penerapan prinsip resiprositas ke dalam hukum perbankan masing-masing negara anggota disepakati dengan pokok ketentuan:48

1) Bagi negara-negara anggota ASEAN yang belum memiliki hubungan homehost, pengaturan prinsip resiprositas ditujukan guna menciptakan peluang pendirian Qualified ASEAN Banks (QABs).

2) Bagi negara-negara anggota ASEAN yang telah memiliki hubungan homehost, maka pengaturan prinsip resiprositas ditujukan guna mengurangi kesenjangan dalam penyediaan akses pasar dan fleksibilitas operasional.

Sistem pengaturan dan pengawasan perbankan Indonesia mengalami perubahan mendasar sejak terbentuknya Otoritas Jasa Keuangan (OJK). Pasca berdirinya OJK sistem pengawasan sektor perbankan dalam aspek makro dan mikro dilaksanakan secara terpisah. Pengawasan terhadap aspek makro dilakukan oleh Bank Indonesia, sementara Otoritas Jasa Keuangan melaksanakan pengawasan terhadap aspek mikro. Baik Bank Indonesia maupun Otoritas Jasa Keuangan telah menyampaikan secara resmi perihal komitmen pemerintah

\footnotetext{
${ }^{47}$ Bank Indonesia, Loc.Cit.

${ }^{48}$ Ibid
} 
Indonesia dalam pelaksanaan ABIF. ${ }^{49}$ Sementara itu, upaya Indonesia terhadap implementasi prinsip resiprositas ABIF juga dilakukan melalui agenda otoritas perbankan Indonesia ${ }^{50}$ untuk mendorong bank-bank nasional guna pemenuhan kualifikasi QABs. ${ }^{51}$

Kriteria QABs merupakan kriteria tertentu yang disepakati oleh masingmasing negara anggota ASEAN. Beberapa diantara kriteria QABs yakni; memiliki permodalan yang kuat (well capitalized), direkomendasikan oleh otoritas perbankan (recommended by authorities), memiliki pengelolaan yang baik (well managed) serta memenuhi ketentuan kehati-hatian sesuai dengan standard internasional (pass the Basel provisions). 52

Standard kehati-hatian sebagai kriteria QABs adalah standard kehati-hatian sebagaimana diatur dalam prinsip Basel. Indonesia telah melakukan pemenuhan terhadap tiga standar utama Basel II dan III. Ketiga standar dimaksud yakni; (1) Basel III-Final Capital Framework Issued, (2) Basel III-Final Liquidity Framework Issued, serta (3) Basel II-full implementation. 53

\section{Penutup}

Berdasarkan analisis di atas, dapat disimpulkan: Pertama, prinsip resiprositas berdasarkan ABIF bermakna sebagai sebuah prinsip dasar hubungan timbal balik antar negara anggota dalam pelaksanaan integrasi perbankan. Hubungan timbal balik berdasarkan ABIF meliputi hubungan timbal balik dalam penyediaan akses pasar dan fleksibiltas operasional antar bank-bank yang berasal dari negara anggota ASEAN. Prinsip resiprositas berdasarkan ABIF tidak berlaku secara serta merta dan tanpa syarat. Berbeda dengan prinsip non diskriminasi sebagaimana diatur dalam WTO, pemberlakuan prinsip resiprositas berdasarkan ABIF didasarkan pada terpenuhinya dua syarat. Pertama yakni tercapainya perjanjian

\footnotetext{
${ }^{49}$ Inda Rahadiyan dan Berliana Rida, loc.cit. Baca pula: Siaran Pers Bank Indonesia, "Indonesia Sepakat Mendukung Integrasi Perbankan ASEAN", http://www.bi.go.id diakses pada tanggal 10 November 2017. Indonesia.

${ }^{50}$ Yang dimaksud dengan otoritas perbankan dalam hal ini adalah Otoritas Jasa Keuangan (OJK) dan Bank

${ }^{51}$ Dalam kontes ini Indonesia dituntut untuk segera mempersiapkan bank-bank nasional yang ada guna memenuhi kualifikasi Qualified ASEAN Bank, sehingga dapat bersaing dengan Bank ASEAN lainnya. Baca: Tri Handayani dan Lastuti Abubakar, "Implikasi Kesepakatan ASEAN Banking Integration Framework terhadap Pembaruan Hukum Perbankan Indonesia”, Jurnal Rechtidee, Volume 11 Nomor 2, Desember 2016, hlm. 139.

52 Marchella Dwi Permatasari, Op. Cit.

${ }^{53}$ Baca: Yati Kurniati, Loc. Cit.
} 
bilateral antar negara anggota atas dasar kesiapan. Kedua yakni terpenuhinya kualifikasi /standard QABs bagi bank-bank negara anggota. Dengan demikian, prinsip resiprositas tidak secara serta merta mengikat seluruh negara anggota ASEAN sejak tercapainya kesepakatan pembentukan ASEAN Economic Community.

Kedua, pemerintah Indonesia terus berupaya melakukan implementasi prinsip resiprositas berdasarkan ABIF. Upaya tersebut dilakukan baik dalam level regulasi maupun dalam level non regulasi. Dalam level regulasi, implementasi terhadap prinsip resiprositas ABIF telah mendapatkan pijakan yuridis yang kuat dengan diterbitkannya Undang-Undang Nomor 4 Tahun 2018 tentang Pengesahan Protokol Untuk Melaksanakan Paket Komitmen Keenam Bidang Jasa Keuangan Dalam Kerangka Kerja ASEAN Di Bidang Jasa. Undang-Undang dimaksud secara eksplisit telah pula menjadi dasar bagi pelaksanaan komitmen integrase perbankan antara Indonesia dengan Malaysia. Sementara itu dalam tataran praktek, upaya Indonesia untuk mengimplementasikan prinsip resiprositas ABIF terus dilakukan melalui upaya pemenuhan bank-bank nasional terhadap kriteria QABs.

\section{Daftar Pustaka}

\section{Buku}

Asian Development Bank, The Road to ASEAN Financial Integration: A Combined Study on Assessing the Financial Landscape and Formulating Milestones for Monetary and Financial Integration in ASEAN, Asian Development Bank, Mandaluyong City, 2013.

Direktorat Kerjasama ASEAN, ASEAN Selayang Pandang Edisi ke-19, Jakarta, 2010.

Fuady, Munir, Hukum Perbankan Modern (Berdasarkan Undang-Undang Tahun 1998) Buku Ke Satu, Citra Aditya Bakti, Bandung, 1999.

Gazali, S Johny dan Rahmadi Usman, Hukum Perbankan, Cet. Ke tiga, Sinar Grafika, Jakarta, 2016.

Hermansyah, Hukum Perbankan Nasional Indonesia, Kencana Prenada, Jakarta, 2005. Ibrahim, Johny, Teori dan Metodologi Penelitian Normatif, Banyumedia Publishing, Malang, 2006.

Jumhana, Muhammad, Hukum Perbankan di Indonesia, Alumni, Bandung, 1993.

Van Den Bosch, Peter, WTO: Text, Cases and Materials, Cambridge University Press, 2008. 


\section{Laporan Penelitian}

Rahadiyan, Inda dan Berliana Rida, "Komitmen Indonesia dalam Penerapan Prinsip Resiprositas Berdasarkan ASEAN Banking Integration Framework", Laporan Penelitian Kolaborasi Dosen dan Mahasiswa, Program Studi Strata Satu Ilmu Hukum, Fakultas Hukum Universitas Islam Indonesia, 2016.

Schill, Stephan W., "International Investment Law and The Rule of Law", Amsterdam Law School Legal Studies Research Paper No. 2017-18, https:/ / www/ilsa.org diakses pada tanggal 8 Desember 2017.

\section{Jurnal}

Dolzer, Rudolf, "The Impact of International Investment Treaties on Domestic Administrative Law", NYU Journal of International Law and Politics Vol. 37, Institute for International Law and Justice, 2005.

Handayani, Tri dan Lastuti Abubakar, “Implikasi Kesepakatan ASEAN Banking Integration Framework terhadap Pembaruan Hukum Perbankan Indonesia", Jurnal Rechtidee, Volume 11 Nomor 2, Desember 2016.

Koesrianti, "Analisa Kekuatan Mengikat Piagam ASEAN dan Perkembangan Mekanisme Penyelesaian Sengketa di ASEAN", Jurnal Yuridika, Volume 26 No. 1, Januari-April 2011.

Permatasari, Marcella Dwi, “Upaya ASEAN Menghadapi Disparitas Finansial Dalam Proses Integrasi Finansial Regional: Studi Kasus ASEAN Banking Integration Framework (ABIF)", Jurnal Analisis Hubungan Internasional, Volume 5 Nomor 3, Oktober 2016.

Rahadiyan, Inda dan Karina Amanda Savira, "Peluang dan Tantangan Atas Keikutsertaan Indonesia Dalam Masyarakat Ekonomi ASEAN", Jurnal Defendonesia, Volume 2 Nomor 1, Desember 2016.

Rillo, Alladin D., "ASEAN Financial Integration: Opportunities, Risks and Challenges", Public Policy Review, Policy Research Institute, Ministry of Finance, Japan, Volume 14, Nomor 5, September 2018.

Gochoco, Maria Socorro and Eli M. Remolona, "The Promises of Bank Integration in ASEAN: Is There a Catch?", ASEAN@50 Volume 5, The ASEAN Economic Community into 2025 and Beyond, 2017.

\section{Internet}

“ASEAN Vision 2020", http://www.aseansec.org diakses pada tanggal 30 Juni 2018.

"ASEAN Banking Integration Framework," http://www.asean.org diakses pada tanggal 27 Agustus 2018

"ASEAN Banking Integration and Lesson from Europe", http://www.bis.org/punl/qtrpdf/r_qt1509z.h diakses pada tanggal 10 Desember 2017. 
"Indonesia Sepakat Mendukung Integrasi Perbankan ASEAN", diakses dari https:/ / www.bi.go.id pada tanggal 10 Desember 2016.

"The Promises of Bank Integration in ASEAN: Is There a Catch?", diakses dari http://www.eria.org/5.5.ASEAN_50_Vol_5_Bautista_and_Remolona.pdf pada tanggal 27 Agustus 2018.

“The Impact of International Investment Treaties on Domestic Administrative Law", https:/ / www.iilj.org diakses pada tanggal 12 November 2018.

"Banking Strategy and Implementation of Banking ASEAN Integration Framework (ABIF) in ASEAN Community (AEC)'s Era 2020" diakses dari https://mpra.ub.uni-muenchen.de/73303 diakses pada tanggal $10 \mathrm{Juli}$ 2018.

"International Investment Law and The Rule of Law", Amsterdam Law School Legal Studies Research Paper No. 2017-18, https://www/ilsa.org diakses pada tanggal 8 Desember 2017 pada pukul 15.10 WIB.

"ASEAN Banking Integration Framework: Advances and Challenges in Regional Integration" diakses dari https://www.imf.org diakses tanggal 10 Desember 2017.

Siaran Pers Bank Indonesia, "Indonesia Sepakat Mendukung Integrasi Perbankan ASEAN", http:/ / www.bi.go.id diakses pada tanggal 10 November 2017.

Kurniati, Yati, "ASEAN Banking Integration Framework: Advances and Challenges in Regional Integration", https://www.imf.org/external/np/ seminars/eng/2016/hit2016/pdf/2-2.pdf diakses tanggal 10 Desember 2017.

Suryasnia, Sofi, et.all., "Banking Strategy and Implementation of Banking ASEAN Integration Framework (ABIF) in ASEAN Community (AEC)'s Era 2020", diakses dari https://mpra.ub.uni-muenchen.de/73303 diakses pada tanggal 10 Juli 2018.

\section{Peraturan Perundang-Undangan}

Undang-Undang Republik Indonesia Nomor 10 Tahun 1998 Tentang Perubahan Atas Undang-Undang Republik Indonesia Nomor 7 Tahun 1992 Tentang Perbankan, Lembaran Negara RI Tahun 1998 Nomor 182.

Undang-Undang Republik Indonesia Nomor 4 Tahun 2018 Tentang Pengesahan Protokol Untuk Melaksanakan Paket Komitmen Keenam Bidang Jasa Keuangan Dalam Kerangka Kerja ASEAN Di Bidang Jasa, Lembaran Negara RI tahun 2018 Nomor 82. 